$11-1-2013$

\title{
CT Angiography in The Detection of Carotid Body Enlargement in Patients with Hypertension and Heart Failure
}

\author{
Sreejit Nair \\ Weill Cornell Medical College
}

Ajay Gupta

Weill Cornell Medical College

Marat Fudim

Vanderbilt University Medical Center

Christopher Robinson

Weill Cornell Medical College

Vinay Ravi

Weill Cornell Medical College Follow this and additional works at: https://engagedscholarship.csuohio.edu/scimath_facpub

Part of the Mathematics Commons

Seew yxtpage for additipnalaythors nefit you? Let us know!

\section{Publisher's Statement}

The final publication is available at Springer via http://dx.doi.org/10.1007/s00234-013-1273-3

\section{Repository Citation}

Nair, Sreejit; Gupta, Ajay; Fudim, Marat; Robinson, Christopher; Ravi, Vinay; Hurtado Rua, Sandra M.; Engelman, Zoar; Lee, Kyungmouk S.; Philips, C. Douglas; and Sista, Akhilesh K., "CT Angiography in The Detection of Carotid Body Enlargement in Patients with Hypertension and Heart Failure" (2013). Mathematics Faculty Publications. 178.

https://engagedscholarship.csuohio.edu/scimath_facpub/178

This Article is brought to you for free and open access by the Mathematics and Statistics Department at EngagedScholarship@CSU. It has been accepted for inclusion in Mathematics Faculty Publications by an authorized administrator of EngagedScholarship@CSU. For more information, please contact library.es@csuohio.edu. 


\section{Authors}

Sreejit Nair, Ajay Gupta, Marat Fudim, Christopher Robinson, Vinay Ravi, Sandra M. Hurtado Rua, Zoar

Engelman, Kyungmouk S. Lee, C. Douglas Philips, and Akhilesh K. Sista 


\title{
CT angiography in the detection of carotid body enlargement in patients with hypertension and heart failure
}

\author{
Sreejit Nair, Ajay Gupta, Marat Fudim, Christopher Robinson, Vinay Ravi, Sandra Hurtado-Rua, Zoar \\ Engelman, Kyungmouk S. Lee, C. Douglas Phillips, Akhilesh K. Sista
}

\section{Introduction}

The carotid bodies are the primary sensors of hypoxemia and the main sensors of carbon dioxide and $\mathrm{pH}$ outside of the brain. They have been found to be hyperactive in various disease states. Historical literature from the 1970s provided evidence that the carotid bodies are enlarged in respiratory disease states (asthma, chronic obstructive pulmonary disease (COPD), and emphysema) [1, 2]. Several human cadaver studies indicated a significant correlation between the com-bined weights of the carotid bodies and the weight of both the right and left ventricles [1, 2]. This finding suggests that the carotid bodies could play a role in the development or pro-gression of cardiovascular diseases like heart failure (HF). Subsequent studies have found carotid body (CB) enlargement in animals with genetic hypertension (HTN; spontaneous hy-pertensive rats) [3-5]. Modern literature provides increasing 
evidence that the carotid bodies play a major role in modulating sympathetic activation in disease states like HF and HTN [6-10].

A recent study investigating the role of neck computed tomography angiography (CTA) in detecting the CB found that the CB can be reliably detected on CTA [11]. To our knowledge, there has not been any prior imaging study correlating CB size to specific disease states. The purpose of this case-control study was to compare $\mathrm{CB}$ sizes in patients with both HF and HTN with those of controls without HF, HTN, or any other potentially confounding conditions (cirrhosis, respiratory disease, lactic acidosis, or hemoglobinopathy) using CTA.

\section{Methods}

The study was approved by the institutional review board. Retrospective review was performed on 323 consecutive patients who had neck CTA exams in 2011. Patients with HF and HTN were identified based on a diagnosis in the medical record within 6 months of the CTA exam. Confounding exclusionary conditions were placed in three main categories: (1) hepatic disorders, such as cirrhosis, (2) pulmonary disorders, such as COPD or chronic interstitial lung disease, and (3) hematologic or metabolic abnormalities, such as lactic acidosis or hemoglobinopathy. Patients with insufficient chart information to confirm the presence or absence of these conditions were excluded from the study. From the 323 neck CTAs screened, 17 adult patients with HF and HTN were identified.

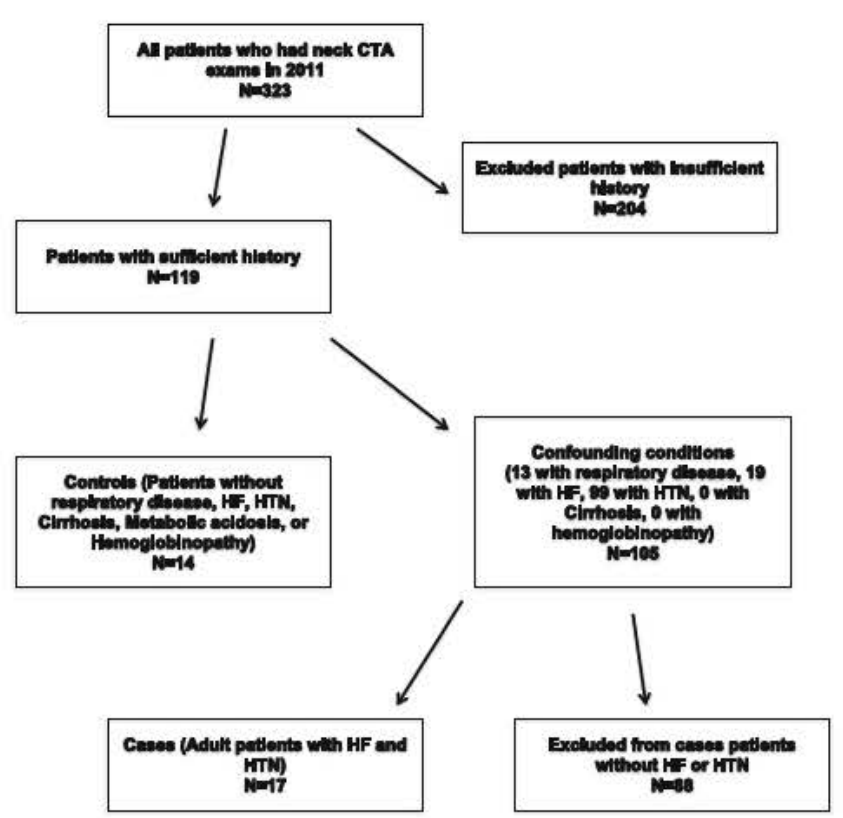

Fig. 1 Patient flow diagram describing the selection of cases and controls
Table 1 Demographics for HF vs. control groups

\begin{tabular}{lll}
\hline & HF and HTN & Controls \\
\hline Median age (years) & 57.1 & 44.0 \\
Gender (male, \%) & 76 & 64 \\
Population size & 17 & 14 \\
\hline
\end{tabular}

Fourteen patients had conclusive information excluding the presence of the above confounding conditions and were identified as controls (Fig. 1).

Two board-certified radiologists blinded to the patients' case or control status made consensus bilateral CB measurements on the CTA exams. Our departmental CTA protocol uses bolus tracking via premonitoring scans at the level of the aortic arch, with an ROI placed within the ascending aorta. Helical $0.625-\mathrm{mm}$ collimated images were acquired from the inferior aspect of the aortic arch to the superior aspect of the frontal sinus, with a pitch of 1.0 at $120 \mathrm{kV}$. One hundred milliliters of contrast was injected through an 18-gauge antecubital fossa intravenous line at a rate of $4 \mathrm{ml} / \mathrm{s}$. The matrix size of the scanner was $512 \times 512$. Measurement tools allowed measurement of differences of $0.1 \mathrm{~mm}$. Measurements were made using a standardized protocol with PACS (picture archiving and communication system) measurement tools at $200 \%$ magnification to determine longitudinal and transverse axial dimensions [11]. The $\mathrm{CB}$ was identified on each side by searching for an avidly enhancing structure in the characteristic location of the $\mathrm{CB}$ at the inferomedial aspect of the carotid bifurcation. Given the consistent oval or elliptical configuration of the $\mathrm{CB}$ on axial images, the difficulties in obtaining an accurate craniocaudal measurement, and the spatial limitations of multiplanar coronal reformatted images,

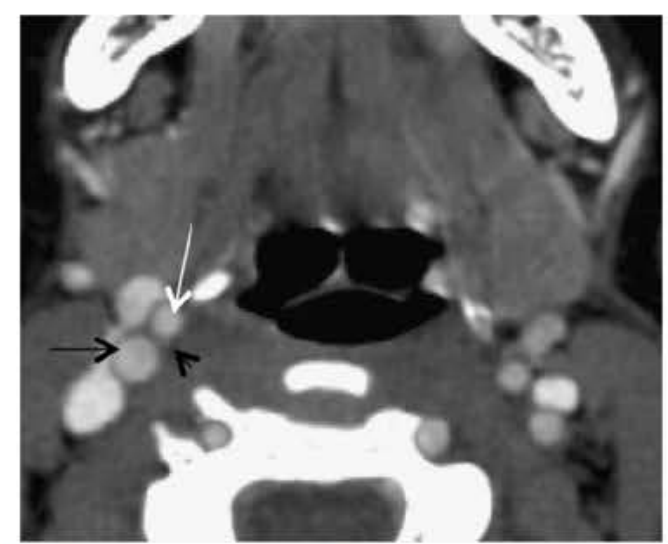

Fig. 2 CTA axial image at the level of the carotid body in a 56 year old male control patient demonstrates normal right carotid body (arrowhead) at the bifurcation of the right internal (black arrow) and external (white arrow) carotid arteries 


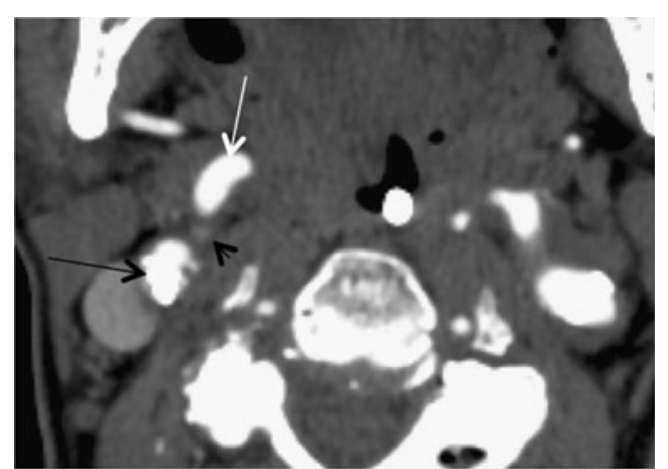

Fig. 3 CTA axial image in a 51 year old male with heart failure and hypertension demonstrates enlarged right carotid body (arrowhead) at the bifurcation of the right internal (black arrow) and external (white arrow) carotid arteries

the axial cross-sectional area of each $\mathrm{CB}$ was computed as the area of an ellipse. A value of 0 was recorded for any $\mathrm{CB}$ not visualized. $\mathrm{CB}$ areas were compared in the case and control groups using a paired $t$ test. The right case CBs were compared with the right control CBs, and the left case CBs were compared with the left control CBs.

\section{Results}

The patient demographic breakdown for HF and HTN patients vs. control groups is given in Table 1. Representative control and case images are shown in Figs. 2 and 3, respectively. The right $\mathrm{CB}$ was identified in $65 \%$ of HF and HTN patients (11/17) and in $57 \%$ of controls (8/14). The left CB was identified in $83 \%$ of HF and HTN patients $(15 / 18)$ and in $36 \%$ of controls $(5 / 14)$. The smallest detected carotid body measured $1 \mathrm{~mm} \times 1 \mathrm{~mm}$ in longitudinal and transverse dimensions in a control patient. The right $\mathrm{CB}$ demonstrated a mean cross-sectional area of $2.79 \mathrm{~mm}^{2}$ in $\mathrm{HF}$ vs. $1.40 \mathrm{~mm}^{2}$ in controls $(p=0.02)$. The left $\mathrm{CB}$ demonstrated a mean cross-sectional area of $3.13 \mathrm{~mm}^{2}$ in HF and HTN patients vs. $1.53 \mathrm{~mm}^{2}$ in controls $(p=0.03)$ (Tables 2 and 3 ). No difference between the right and left CBs was detected in either group. While the right- and left-sided CBs in the HF and HTN groups showed a strong positive correlation, the $\mathrm{CBs}$ in the control group showed no or only negligible positive correlation (Tables 4 and 5).

Table 2 Comparison of cross sectional areas of the right CB in $\mathrm{HF}$ and HTN groups versus control

\begin{tabular}{llll}
\hline & HF and HTN & Control & $p$ value \\
\hline Mean size $\left(\mathrm{mm}^{2}\right)$ & 2.51 & 1.06 & 0.04 \\
Variance $\left(\mathrm{mm}^{2}\right)$ & 5.35 & 1.31 & \\
\hline
\end{tabular}

Table 3 Comparison of cross sectional areas of the left CB in HF and HTN groups versus control

\begin{tabular}{llll}
\hline & HF and HTN & Control & $p$ value \\
\hline Mean size $\left(\mathrm{mm}^{2}\right)$ & 2.99 & 1.03 & 0.02 \\
Variance $\left(\mathrm{mm}^{2}\right)$ & 6.49 & 2.87 & \\
\hline
\end{tabular}

\section{Discussion}

The CB may contribute to increased sympathetic activation in cardiovascular diseases like HF and HTN [10]. Prior pathologic studies have uncovered a positive correlation between the increased size of the CB and the presence of these disease states $[1,12]$. Proposed mechanisms for hyperactivity and enlargement of these chemoreceptors include decreased perfusion, changes in acid-sensing ion channels, and shifts in the relative activities of hypoxia-inducible factors (HIF1 and HIF2) [12-15]. Analysis of the CB in an animal model of genetic HTN showed the glomus cells to be hypertrophied, suggesting an increase in protein synthesis and angiogenesis [16].

The CB is a highly perfused organ [17], making it visible on CTA. In 2011, Nguyen et al. confirmed the ability to consistently detect the carotid body in a series of patients who underwent CTA for various indications [11]. In our retrospective blinded case-control study of 17 patients with HF and HTN and 14 controls, we tested the hypothesis that CTA can be used to show enlargement of the CB in HF and HTN. We found that the CB cross-sectional areas measured on CTA are significantly increased in HF and HTN compared to controls. Similar to Nguyen et al., we have shown a positive correlation between the size of the right and left CBs. However, we show this correlation only with HF and HTN patients and not with the control population, possibly due to our relatively smaller sample size.

The pathophysiologic significance of the $\mathrm{CB}$ in $\mathrm{HF}$ and HTN has been recognized in both historical and more recent literature $[10,18]$. Interestingly, overactivity of the CB has been linked to a higher mortality rate in patients with $\mathrm{HF}[10$, 19]. Importantly, it is still unclear whether this overactivity is a cause or effect of its anatomical size. The temporal relationship between CB size changes and the onset of HTN and CHF is also unclear. However, as seen in this study, CTA may be a non-invasive tool to visualize the $\mathrm{CB}$. With further validation and confirmation, the ability to reliably detect "pathological"

Table 4 Comparison of cross sectional areas of the right and left CBs in HF and HTN groups

\begin{tabular}{lllll}
\hline & Right & Left & Pearson coefficient & Student's $t$ test \\
\hline Mean size $\left(\mathrm{mm}^{2}\right)$ & 2.51 & 2.99 & 0.41 & 0.57 \\
\hline
\end{tabular}


Table 5 Comparison of cross sectional areas of the right and left CBs in control group

\begin{tabular}{lllll}
\hline & Right & Left & Pearson coefficient & Student's $t$ test \\
\hline Mean size $\left(\mathrm{mm}^{2}\right)$ & 1.06 & 1.03 & 0.14 & 0.94 \\
\hline
\end{tabular}

$\mathrm{CB}$ enlargement with CTA may make it the imaging modality of choice for monitoring treatments aimed at modulating $\mathrm{CB}$ activity. Since radiation exposure is a potential hazard of CTA, the utility of MRI/MRA in this setting should also be investigated.

Given the retrospective nature of this study and the limitations of chart review, there may have been some degree of inaccuracy selecting cases and controls. However, to limit this potential bias, we were strict in including only cases and controls with adequate chart documentation of inclusion and exclusion criteria. Altitude also may affect $\mathrm{CB}$ size and function, but the retrospective nature of the study did not allow us to collect this specific information. Most patients, however, were drawn from the New York City metropolitan area and were therefore near sea level. A second limitation was our relatively low $\mathrm{N}$. The small sample size limited our ability to perform additional and potentially informative analyses such as correlating ejection fraction/blood pressure with $\mathrm{CB}$ size and distinguishing between the effects of HF and HTN on CB size. This small sample size may also account for the greater variation in $\mathrm{CB}$ size compared with that of Nguyen et al. However, the significant difference between the CB crosssectional areas of HF and HTN cases and controls demonstrates that our study was sufficiently powered to provide meaningful preliminary data regarding our primary outcome measure. A high percentage of the left CBs were not visualized in our analysis; it is possible that such an observation may be due to suppression by the contralateral hypertrophied CB. Further studies will hopefully clarify the influence of one carotid body on the other. Validation of these results will require additional prospective studies with larger patient populations.

\section{Conclusion}

Our case-control series provides CTA evidence that the carotid bodies are enlarged in HF and HTN. CTA could potentially guide and monitor future therapies directed at carotid body overactivity. Further validation of these results with a larger prospective study is required.

Conflict of interest M.F. consults for Cibiem, Inc. Z.E. is an employee of Cibiem, Inc.

\section{References}

1. Heath D, Edwards C, Harris P (1970) Post mortem size and structure of the human carotid body. Thorax 25:129 140

2. Edwards C, Heath D, Harris P (1971) The carotid body in emphyse ma and left ventricular hypertrophy. The Journal of Pathology 104:1 13

3. Habeck JO, Huckstorf C, Honig A (1984) Influence of age on position, shape and size of the carotid bodies in spontaneously hypertensive (SHR) and normotensive (NCR) rats. Anatomischer Anzeiger 157:351 363

4. Honig A, Habeck JO, Pfeiffer C, Schmidt M, Huckstorf C, Rotter H, Eckermann P (1981) The carotid bodies of spontaneously hyperten sive rats (SHR): a functional and morphologic study. Acta Biologica et Medica Germanica 40:1021 1030

5. Heath DSP (1992) Diseases of the human carotid body. Springer, London

6. Izdebska E, Izdebski J, Trzebski A (1996) Hemodynamic responses to brief hyperoxia in healthy and in mild hypertensive human subjects in rest and during dynamic exercise. Journal of Physiology and Pharmacology 47:243 256

7. Tafil Klawe M, Trzebski A, Klawe J, Palko T (1985) Augmented chemoreceptor reflex tonic drive in early human hypertension and in normotensive subjects with family background of hypertension. Acta Physiologica Polonica 36:51 58

8. Ding YFLY, Cornish KG, Schultz HD (2007) Reduced blood flow in carotid arteries is a trigger contributing to peripheral chemoreflex hypersensitivity in chronic heart failure rabbits. FASEB 21:A1268

9. Schultz HD, Li YL (2007) Carotid body function in heart failure. Respiratory Physiology \& Neurobiology 157:171 185

10. Paton JF, Sobotka PA, Fudim M, Engleman ZJ, Hart EC, McBryde FD, Abdala AP, Marina N, Gourine AV, Lobo M, Patel N, Burchell A, Ratcliffe L, Nightingale A (2013) The carotid body as a therapeu tic target for the treatment of sympathetically mediated diseases. Hypertension 61:5 13

11. Nguyen RP, Shah LM, Quigley EP, Harnsberger HR, Wiggins RH (2011) Carotid body detection on CT angiography. American Journal of Neuroradiology 32:1096 1099

12. Habeck JO (1991) Peripheral arterial chemoreceptors and hyperten sion. Journal of the Autonomic Nervous System 34:1 7

13. Li YL, Schultz HD (2006) Enhanced sensitivity of Kv channels to hypoxia in the rabbit carotid body in heart failure: role of angiotensin II. The Journal of Physiology 575:215 227

14. Tan ZY, Lu Y, Whiteis CA, Simms AE, Paton JF, Chapleau MW, Abboud FM (2010) Chemoreceptor hypersensitivity, sympathetic excitation, and overexpression of ASIC and TASK channels before the onset of hypertension in SHR. Circulation Research 106:536 545

15. Prabhakar NR, Semenza GL (2012) Gaseous messengers in oxygen sensing. J Mol Med (Berl) 90:265 272

16. Clarke JA, Daly MD, Ead HW (1993) Vascular analysis of the carotid body in the spontaneously hypertensive rat. Advances in Experimen tal Medicine and Biology 337:3 8

17. Barnett S, Mulligan E, Wagerle LC, Lahiri S (1988) Measurement of carotid body blood flow in cats by use of radioactive microspheres. Journal of Applied Physiology 65:2484 2489

18. Abdala AP, McBryde FD, Marina N, Hendy EB, Engelman Z, Fudim M, Sobotka PA, Gourine A, Paton J (2012) Hypertension is critically dependent on the carotid body input in the spontaneously hyperten sive rat. The Journal of Physiology 590:4269 4277

19. Ponikowski P, Chua TP, Anker SD, Francis DP, Doehner W, Banasiak W, Poole Wilson PA, Piepoli MF, Coats AJ (2001) Periph eral chemoreceptor hypersensitivity: an ominous sign in patients with chronic heart failure. Circulation 104:544 549 